\title{
HEALTH CARE ACCESS IN DEVELOPING NATIONS: A MACRO ANALYSIS OF THE PROBLEMS AND POLICY SUGGESTIONS FOR INDIA
}

Nisha Sara Varghese* and Ajith Kesavan Unni**

\section{The Indian Scenario: An Evaluation of the Health Care Sector and its Fallacies}

India's expenditure in the health care sector is considered awfully inadequate owing to the sheer geographic and demographic size. Public spending on health is just $0.9 \%$ of the GDP, which forces the citizens to pay as much as $82.7 \%$ of total expenditure on health by themselves [WHO Statistics]. This phenomenon is common across the developing nations - 80 per cent of world's population spent only 10 per cent of the total expenditure on health.

* Student of UG Economics, Christ College, Hosur Road, Bangalore 560029 nisha.varghese@gmail.com

** Student of UG Economics, Christ College, Hosur Road, Bangalore 560029 ajith.unni@yahoo.com

Research Paper Submitted for the South Asian Economics Student's Meet - 2008 
Over the years, there was a sharp decline in the government expenditure in public health. The expenditure is borne unequally by the central and state governments; and the debt ridden states have cut on public spending on health. The government expenditure on health care sector cannot be sidelined in any nation, especially in a developing nation like India as if forms the fulcrum balancing quality health and affordability for a large section of population. But ironically, there is a skewed graph of demand versus supply in the Indian scenario. While $75 \%$ of Indian population lives in semi-rural and rural areas, $84 \%$ of the hospital beds exist in urban areas. ${ }^{1}$ This is the outcome of a pro-private attitude taken by governments for the past forty years and gradual pulling out from the market as such. The investment made in physical and capital health care infrastructure does not even keep up with the pace of population growth, while the private health care systems have flourished into a multi-billion dollar industry. Between 1987 and 1996, there was a shocking $30 \%$ decline in the use of public health care facilities in both rural and urban areas. ${ }^{2}$ Such a tendency is synonymous with rising inequity in access to health care itself. High costs have translated it to:

- Hospitalized Indians spending $58 \%$ of their annual income on health care

- Heavy debt burden, between $40 \%$ (urban) to $60 \%$ (rural) of total cost of health care

- Inaccessibility on account of less push to attend to health problems and high costs $^{3}$

The problems of an ill equipped government health machinery and a growing private health care system penetrates all strata of the society - while the urban poor finds it costly, the rural society lives with a non-existent infrastructure, and these areas are not attractive for continuous private investments. Such a situation is pathetic, in a situation where all capitalist and socialist societies, even with low per capita spending like Costa Rica have successfully implemented universal health care systems where public sector's share in the burden is between 60 to $100 \%$, through state revenues and/or social insurance, has been the critical component in realizing universal access with equity.

Access to medical treatment should not entirely depend upon an individual's ability to pay. But this is increasingly the case in countries that cannot assure universal health care access to its citizens, especially the poor. A household which does not possess the capacity to meet the medical expenses will ultimately fall into the vicious circle, forcing members to cut expenses on food, nutrition, social well being etc and also more work hours. The financial risk protection mechanisms are mainly limited to private health insurance which only the middle class and rich can afford. ${ }^{4}$ 
The majority of Indian population lacks awareness on insurance and third party coverage schemes, which hinders the growth of its market. The insurance companies find it unviable to penetrate the rural market, which is more or less completely ignorant of the working of insurance schemes. Even the current urban market for these schemes is an outcome of opening up of insurance market to private players, who in turn took the initiative to educate and enlighten the urban population in its competition to garner the larger share of the market. This can be seen as a positive development, but there is a long way to go from this point.

\section{Policy Suggestions}

To achieve the primary goal of improving people's access to health care, both public and private health providers to be more sensitive and responsive to people's needs. Not only does it call for a change in individual attitudes, but also a larger commitment on the part of the government to put in place all of the things that would result in better health care access for its citizens, especially the poor. The biggest challenge is to work out a strategy to achieve this goal in a society as diverse as India. A universal health care system like that of UK or Germany would prove futile as it would still indirectly deny the services to a section which lacks access to basic health care. A high Gini coefficient of 0.42 in India goes against the solution of completely privatizing the health care sector. As a possible path, the following suggestions can be considered.

The primary aim is to account for the difference in health care infrastructure across India's rural and urban centers. While there exists as many as 1 bed per 490 people in the urban population due to high creation of hospital beds by the private sector, it's as low as 1 bed per 4900 people in the rural areas. The health infrastructure in the urban areas is sufficient to cater to the needs of the urban population but the inflating prices of medical services create an excess capacity. This excess capacity is not as a result of lack of demand but out of the high cost which makes it inaccessible for a majority in the urban area.

What India requires is a comprehensive macro approach which involves redistribution of the existing services and making it more accessible while keeping a control on medical inflation. This approach will require inducing a demand for health care services among the population, while the out of pocket expenditure for the user is brought down to the levels of a developed nation. The entire exercise should be formulated keeping in mind the utility maximization principle and the demandincome relationship existing in a developing nation.

The present government expenditure on health care is merely Rs 22500 crores which has not been effectively channelized. As of now, the budgetary allocation is more on ineffective schemes that fail to cover the population that actually requires 
it. What is of utmost importance is creation of physical health care infrastructure in rural areas. This can be achieved by increasing the government spending, especially in improving the rural health care services. This involves setting up of hospitals and rural clinics which ought to be free for the poorer sections of the society. The section which has capacity to afford it, the services should be pay-as-you-use, for there exists very less options to insure themselves. In due course, the private insurance companies should penetrate and cover the rural population that can afford a third party cover for their medical expenses. Gradually, it will reduce the out of pocket expenditure of that class, while the poorest of the poor will still be protected under government subsidy. This policy believes that in the longer run, the poor will gradually climb the economic ladder, and reach a stage wherein they can afford health care by themselves. The gradual course of action to be taken by the government is to further cover boost the private sector to invest in physical health care capital in rural areas, as the number of people benefiting directly from government subsidy reduces. The government's role in the longer term ( $25+$ years) will be reduced to the caretaker of the existing systems in rural and urban areas, while maintaining the highest quality standards and freely accessible to the poor sections of the society.

The urban population, which is fairly well accounted and registered for, will require a different approach altogether. In a nation where vehicles require compulsory insurance to be road worthy, a citizen is not obliged to any such protections. The health care infrastructure existing in urban India can be compared to that of a fairly well developed nation: the better off among the society is able to afford it too. The primary goal of the policy should be to ensure that the unhealthy is given adequate services and options. Riding on the compulsory birth registration act existing in Indian municipalities, the policy can be implemented, covering the entire population.

The urban well off need to be compulsorily insured with a coinsurance rate determined by their income levels, offered by a private or public enterprise. This has to be ensured while registering the birth itself, and any negligence from the user's side should be dealt with higher premiums. The urban poor, who cannot directly access the health care services, especially the private care, should be covered under a premium-free insurance plan, which is to be funded through the previously mentioned higher public spending. This will, to an extent, bring about a demand for health care by that population, indirectly increasing their incomes by lesser loss of man power. The gradual increase in income (ceterus paribus) should in the longer run bring more people under the third party cover, reducing the burden on government exchequer.

Ultimately, the role of the government should be reduced to as a protector of the poor while as a saviour of the consumers from the medical inflation looming large with the onset of private health insurance companies. In order to fulfill the social obligations and the expected rise in budgetary allocation, a certain percentage of profits arising from the private health care insurances should be made to share 
with the government. This won't act as a hindrance as the government indirectly is creating a market by advocating a pro-private stand. All this drastic changes need to be done under strict regulatory authorities and an efficient and task worthy governmental support machinery.

The suggestion given above indirectly advocates a partial government and private sector coordinating to enhance the people's access to health care while reducing the burden on individuals. The partnership varies according to the condition (rural poor, urban rich etc.) since a universal health care policy is impossible in India owing the diversity and disparity.

The investments required to bring about such a sweeping change is not small - to achieve half the world average of 4 beds per 1000 people, 2.15 million beds need to be added. At the rate of Rs. 25 lakh per bed, the expected cost is Rs 550,000 crores or USD 125 billion. This mammoth burden cannot be shouldered on the government alone, and requires active participation from private sector. As advocated earlier, the state expenditure should be spread on creation and maintenance of health care infrastructure and subsidizing the 'real' poor. Another major hurdle is the inaccessibility due to lack of support infrastructure like roads and transport services to the network for people of remote areas. This should also be included in the provisions formulated, while keeping the expenses incurred completely away from the health budgets.

The biggest challenge of all is to convince a government whose defence budget runs into Rs. 96000 crores, while a paltry Rs. 15000 crores is the budget to save the 400 million people who simply cannot afford health care.

\section{References \& Notes:}

- Santere, Renford E. and Neun, Stephen P.; Health Economics: Theories, Insights and Industry Studies; Irwin Publishers.

- Jack, William; Principles for Health Economics for Developing Countries; WBI Development Studies - The World Bank, Washington D.C.

- Black Jr., Kenneth and Skipper Jr., Harold D; Life Health Insurance; 2000; Pearson Education

- McGuire; Alistair, Henderson; John and Mooney, Gavin; The Economics of Health care- An introductory text; Routledge, New York.

1. Duggal, Ravi, The Private Health Sector in India: Nature, Trends and a Critique, January 1996.

2. Duggal, Ravi; The out-of-pocket Burden of Health care.

3. Government Health Expenditure in India: A Benchmark Study - Undertaken for the Macarthur Foundation, India.

4. Iyer, Aditi; III and Impoverished: The Medical Poverty Trap; InfoChange News \& Features, June 2005. 